\title{
Sources of Cardiovascular Health Information and Channels of Health Communication among Urban Population in Nigeria
}

\author{
Ejiofor A. Ezika ${ }^{1}$, Beth Cross ${ }^{2}$, Moira Lewitt ${ }^{3}$ \\ ${ }^{1,3}$ School of Health, Nursing and Midwifery, University of the West of Scotland, UK \\ ${ }^{2}$ School of Education, University of the West of Scotland, UK
}

\begin{tabular}{l}
\hline Article Info \\
\hline Article history: \\
Received Dec 28, 2017 \\
Revised Feb 25, 2018 \\
Accepted Mar 15, 2018 \\
\hline
\end{tabular}

\section{Keyword:}

Health communication Health information

Media channels

Nigeria

Public health

\begin{abstract}
This study employed mixed methods to investigate the preferred sources of health information and later explored the views of community healthcare workers on the enablers, barriers and ways of overcoming barriers to health communication. The study found that majority of the participants preferred their source of CV (cardiovascular) health information from the healthcare workers including the medical doctors, nurses, and pharmacists. On the other hand, the least preferred source of health information was from friends, family members, and community leaders. Some of the identified enablers to community health communication include awareness programme via NonGovernmental Organisations (NGOs), community-based organisations such as faith-based organisations and healthcare facilities. Others are traditional media and social media. The identified barriers to community-based health communication include lack of knowledge and poverty, language barriers, and other miscellaneous issues including misuse of internet, lack of basic amenities and religious beliefs. The community-based healthcare providers articulated ways to overcome the identified barriers, including enlightenment programmes, using the language of the target audience, funding health awareness programmes, and monitoring of health education interventions. This study concludes that dissemination of health information using numerous channels is essential in ensuring population-wide primary prevention of diseases.
\end{abstract}

Copyright (C) 2018 Institute of Advanced Engineering and Science. All rights reserved.

\section{Corresponding Author:}

Moira Lewitt,

School of Health, Nursing and Midwifery,

University of the West of Scotland,

High Street, Paisley, PA1 2BE, United Kingdom.

Email: Moira.lewitt@uws.ac.uk

\section{INTRODUCTION}

Health communications and social marketing campaigns use multiples channels to raise awareness and provide culturally appropriate messages about the disease, environmental conditions, nutrition, safety, literacy among other issues to open up access to new knowledge and effect a behaviour change [1]. In developing economies, it is very challenging to disseminate information to the public because many live in demographic contexts that are hard to reach and because communication means are often limited [2]. The prerequisite for eliminating health inequalities is for public health professionals to expand their use of health communication strategies with the aim of affecting individual, community, organisations and policy formulations. This approach can contribute to addressing the multiple determinants of health that give rise to health inequalities [3].

The evidence highlighting the importance of diversification of health communication approaches to improve CV health outcomes informed the research objectives of this study. The aim was to investigate the preferred sources of $\mathrm{CV}$ health information in an urban population in Nigerian as well as explore the 
perceptions of community healthcare providers and health promotion practitioners on enablers, barriers and ways to overcome barriers to health communication within the community. The complexity of culture should be understood before intervention to inculcate cultural variables into health communication efforts [3]. Understanding the target audience health needs is essential to determine the channels that will be employed to reach them. Every channel is different and has different engagement, content, and community norms [4].

\section{METHODS}

The methodology adopted for this study is mixed methods sequential explanatory design. The mixed-methods sequential explanatory design consists of two distinct phases, including quantitative and qualitative phases respectively. The qualitative data are collected and analysed second in the sequence to help elaborate on the quantitative results obtained in the first phase [5]. This study involved two sampling methods including convenience and purposive sampling. This study employed convenience sampling to recruit 50 participants via word of mouth, posters, handbills and community networks. The inclusion criteria for participants that took part in the study reflected three composite attributes. The participants were Nigerians residing in a given urban demographic contexts who understand and speak English, and between the ages of 20-80. However, those that participated in the study were between the ages of $20-59$. Exclusion criteria include non-Nigerians, Nigerians outside the age bracket (20-80), and Nigerians residing outside the given urban geographical area. Questionnaires were administered to the 50 participants to identify their preferred sources of health information. Later on, ten community healthcare workers and health promotion professionals among the 50 participants were purposively selected, and their views on enablers, barriers and ways of overcoming barriers to community health communication were explored using semi-structured interview guide. A Spearman's rank correlation was run to determine the relationship between participants' preferred sources of health information. Homogenous sampling technique was used, in which the selection criteria was based on shared similar characteristics regarding occupation [6]. One-to-one interviews with each of the healthcare workers and health promotion professionals lasted $45-60$ minutes. The sequencing and approaches to key questions were changed depending on the details that needed to be drawn out [7]. An approach to thematic analyses presented by Braun and Clark was used to analyse the qualitative data [8].

\section{RESULTS}

The age distributions of the participants are demonstrated in Figure 1. The majority of the participants were among the age group of 30-39. The participants between the age group of 50 - 59 were fewest.

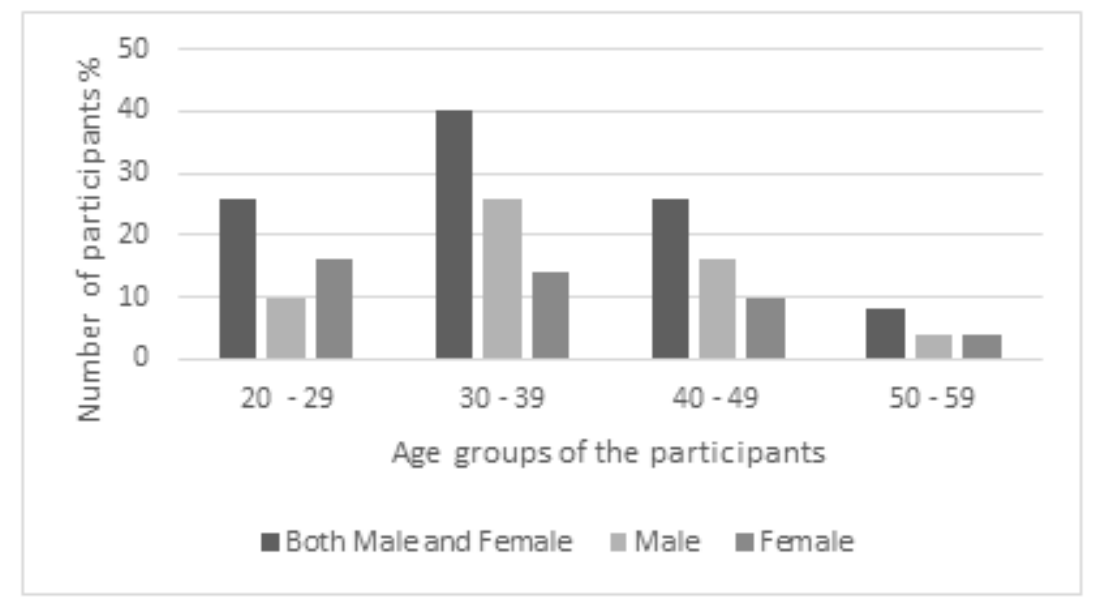

Figure 1. Age groups of the participants

The age group 30 - 39 has the highest number of participants whereas the age group 20 - 29 and 40 - 49 have an equal number of participants. The age group $50-59$ have the least number of participants. The figure below depicts the gathered information on participants preferred sources of health information. The preferred sources of public health information within the community where the public health intervention 
was undertaken are shown in Figure 2. Fivety participants were asked to identify their preferred sources of health information.

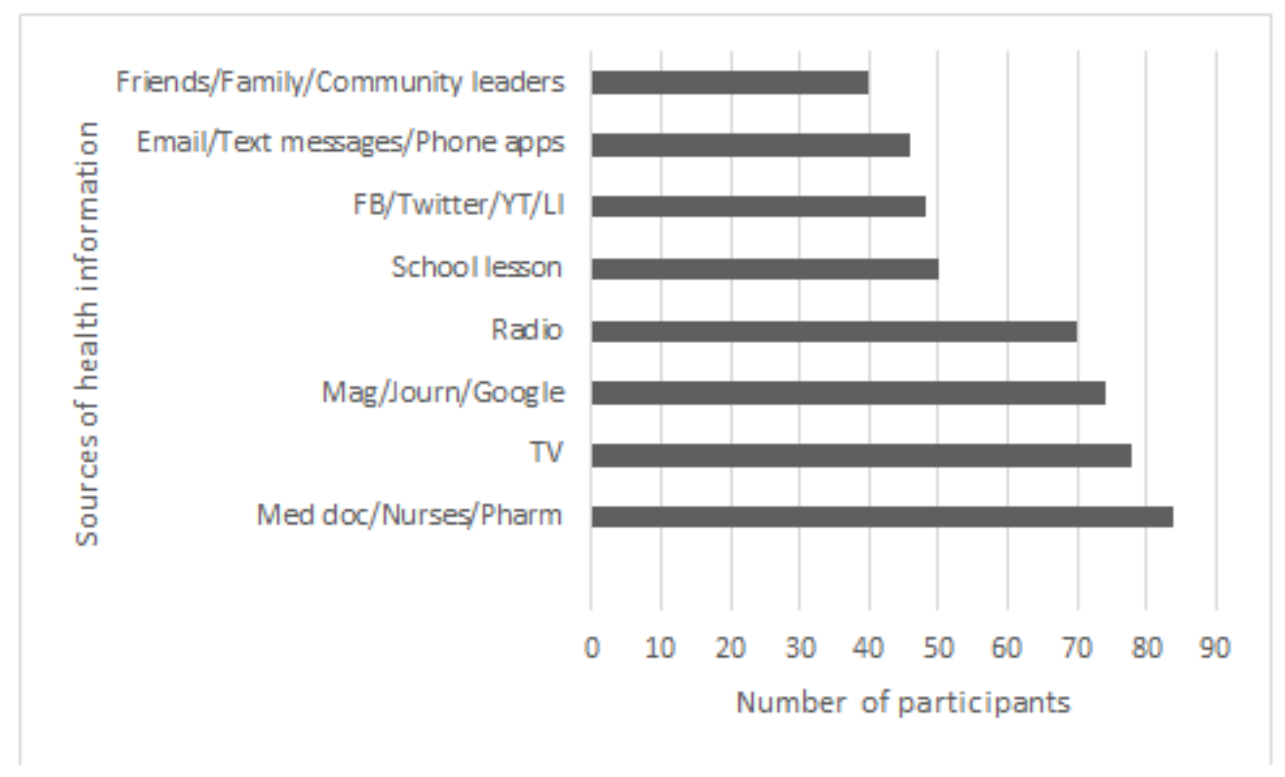

Figure 2. Sources of health information in the community

Spearman's rank correlation was run to determine the relationship between participants' preferred sources of health information. Strongest correlation was found between those who preferred health information from emails/text messages/phone apps and those who preferred information from Facebook/Twitter/YouTube/LinkedIn $\left(\mathrm{r}_{\mathrm{s}}=0.6394, \mathrm{n}=50, \mathrm{p}=0.0000\right)$. The reason for the relationship could be as a result of the fact that the former and latter group share one key feature in common which is being part of modern media. It is interesting that there is no correlation between those who preferred their health information from medical doctors/nurses/pharmacists and those who preferred their health information from any other source (e.g. $\left.r_{s}=0.0316, n=50, p=0.8275\right)$. In light of this observation, it is important for the medical doctors/nurses/pharmacists to devise other means to create awareness about $\mathrm{CV}$ health, including signposting their patients to relevant health magazines and journals or TV health programmes since they were unlikely to be accessing information from other sources or using other self-help materials. There was a moderate relationship between those who preferred their source of $\mathrm{CV}$ health information from friends/family/community leaders and those who preferred their source of health information from television $\left(\mathrm{r}_{\mathrm{s}}=0.4336, \mathrm{n}=50, \mathrm{p}=0.00017\right)$.

\subsection{Enablers to community health communication}

In exploring the questions on the enablers of community health communication in the community, the following themes emerged:

\subsubsection{Awareness programmes via non-governmental organisation (NGO's)}

The participants highlighted that awareness programmes via NGO's as channel of communication promote community health education. The NGOs activities that the respondents were aware of were quite wide-ranging.

'Awareness programmes, for example during the last Ebola outbreak in Nigeria, information was disseminated on what to do like watching of hands' - P2 1

Some community-based healthcare workers suggested that conducting free medical check-up and using peer education can be used as vehicles to promote health education. 
'Conducting free checks, if government, NGO's, can come out and do free checks for people if they can be able to reach people that can't afford to pay for it, they can pass health information through these means' - P45: 2

'There is a need to bring it (health communication) to lowest level, for example, a village woman talking to a village woman' - P1:6

\subsubsection{Community organisations}

The participants highlighted various community channels that enable community-based health education. These community channels include faith-based organisations, schools and primary healthcare facilities, pubs, and supermarkets.

'The best channel is the one that can reach the village. There must be a way to integrate all the channels. One of the channels could be a religion but if somebody is going to sit in an office in Abuja (Federal Capital of Nigeria) and pass the (health) information via the television or radio and my mum in the village has not seen power supply for a month how is that going to work? My mum may not even know how to on (turn on) the television or may not even have access to television such approach (use of television only) can never be effective in Nigeria for now' - P1:8 - 9

Some argued that churches and other faith-based groups enable community health-communication, others suggested it is not a common practice in Nigeria.

'Nigeria is a very religious country, and people tend to listen more to their religious leaders than the (government) authorities. As a result, the church is a good platform to reach many people with health information' - P8:10 - 11

It appears disease outbreak is a factor that influences the use of the church as a platform for health promotion in Nigeria.

'It is not very common for people to use churches to pass health information unless when there is an outbreak' - P25:9

Increasing the use of faith-based organisations as a community resource for health promotion in Nigeria is important in minimising health inequalities. Some participants in the current study stated that schools, stadium, and healthcare facilities serve as channels for community health communication.

'The government may decide to use pubs, schools, hospitals, billboards depending on the group they are targeting. If the government is trying to target youth, they may want to use the stadium. The schools, supermarkets.... the real issue is, are they ready to do it? The implementation is the issue' P1:10

Some posit that town crying is essential as it delivers health information in the language of the target audience which help assimilation of the information. Others admitted that town crying may still be needed in the rural communities but no longer common in today's world.

'Using town criers is one of the best options, people can access information in their language, and the information will sink' - P1:11

'I don't think they still use town crying (laughs) even in other local communities, but it may help to gather the people together, then the health professional would now talk to the people' - P18: 12

\subsubsection{Traditional media} information.

Majority of healthcare workers stated that health programmes on TV and radio promote health

'When there was a case of Ebola in Nigeria, the health authorities liaise with TV, radio and newspaper outfit to create awareness' $-\mathrm{P} 25: 4$

The participants in this study pointed out that wrong timing of health education programmes on television could be a barrier to reaching a large population. 
'At least I can assure you that every home in Nigeria has television; it (TV) is very common, but the only problem is that a lot of people may miss the opportunity to watch a health programme when it is being aired because they may not be at home' - P18:6

Some community-based healthcare workers argue that radio is easier to access than TV.

'Radio is even more common as a means of health communication, there are small pieces of equipment that has radio, phones have radio, cars have radio, even if you enter commercial buses you see them playing radio, radio is very common as a channel of health communication' $-\mathrm{P} 45: 7$

Some community-based healthcare practitioners questioned how often TV and radio are used to disseminate health information.

'Although there are television and radio in Nigeria, the question is how many people (health professionals) do use it for health information dissemination' - P1:2

\subsubsection{Social media and phone apps $T$}

The community healthcare workers stated that social media such as Twitter, WhatsApp and Facebook as well as phone apps as means of modern communication facilitate dissemination of health information within the community. Affordability of data and broadband seemed to be important factors in using social media for health communication in the community.

'The youth are very active in social media because communication outlet now rollout broadband which is cheap and affordable and many people access information through their phones, Facebook and twitter unlike before when you have to go to cyber cafe' - P8: 5

In this study, some healthcare workers suggested that the use of the internet is more common among the educated and younger population.

'Internet is mainly for the educated ones. People use internet to solve problems for themselves, people both in the rural and urban communities use it but depending on the levels of education of the person' - P30: 8

\subsection{Barriers to health communication}

The themes that emerged from exploring barriers to health communication are shown below.

\subsubsection{Lack of knowledge and poverty}

The community healthcare workers were asked to mention the key barriers to the community health communication. In responding to the question, the majority of healthcare workers identified lack of education and poverty as barriers to health communication in Nigeria.

'My grandmother in the village if you tell her she should not eat chicken (infected chicken) due to avian influenza, she would laugh at you and go ahead and still eat the chicken' - P37:16

Some community-based healthcare workers added that in addition to ignorance, lack of fund and poverty affect people's ability to adhere to health education given to them.

'During the case of Ebola outbreak, there was a campaign for people not to eat bushmeat (meat from wild animals) ... but there are some people their sources of income are from selling bush meat and their only source of protein fresh is from bushmeat so they cannot adhere to the teaching (health education) that can change their lives' - P45:13

A community-based healthcare worker expressed concern that Nigerian government may be financially handicapped to continue to make sustainable awareness on public health issues.

'Another challenge I may mention is poor funding from the Nigerian government. Money is a resource that gets exhausted. For you to keep making awareness about a health issue money need to be involved' - P18:18 


\subsubsection{Language}

Some community-based healthcare workers posit that language could be a barrier to community health communication. They reasoned that even with the traditional and social media, information may still be difficult to get to the rural communities.

'Language could be a barrier; if you don't understand the language of the people, you might find it difficult to render services to the people you want to serve' - P45: 2

'One of the barriers as far as our community is concerned is the inability of the information to get to the target group. Even if the information is passed through these channels, some people may not get the information; for example, let me say the people in rural community' - P1:15

However, the participants in this study are of the opinion that the use of jargon is no longer a barrier to community health communication in Nigeria since the practice stopped over a decade ago.

'It does happen (use of jargon in health communication) but in recent years, let me say from the year 2000, the expert now break down the big words ... they don't include those words again. When you look at the pamphlet (health resource materials), it is sometimes written in three major languages in Nigeria' - P8: 20

\subsubsection{Miscellaneous issues}

The community-based healthcare workers highlighted other miscellaneous issues that constitute barriers to community health communication including, misuse of internet, and lack of basic amenities. For example, the community-based healthcare workers pointed out that misuse of internet and lack of basic amenities such as power supply could pose a threat to community health communication.

'During Ebola case in Nigeria, there were cases of loss of lives due to abuse of new communication system; people were sending messages via SMS and all that to their family and friends to drink plenty of salt water and have a bath with it, that is how bad the abuse of modern communication gadget could be' - P30:21

Other concerns highlighted by the community-based healthcare workers include issues related to power failures, corruption, and religious belief.

'When there is no light (power failure) people cannot watch news' - P38:4

'The insincerity of the people that supposed to implement the health communications is the major issue; the fund may be diverted for personal use' - P30: 29

'Another barrier is the religious belief, for example...if you look at the issue of polio (poliomyelitis) vaccination...some Muslim leaders in northern Nigeria discourage their subjects from taking polio vaccines as they believe it can make their women infertile and depopulate them' - P1: 25

\subsection{Overcoming the barriers to health communication}

The themes that emerged on how to overcome barriers to health communication are discussed below.

\subsubsection{Enlightenment programmes}

The community-based healthcare workers opined that it is important to enlighten the religious leaders, especially Islamic leaders on the importance of encouraging Muslims to participate in health protection activities such as immunisation.

'Enlighten people very well, especially in the northern part of this country where religion plays a very big (an important) role ... in the case of polio, some northern islamic leaders believe that it is against their religion to immunise their children, (and would) go ahead and kill people that would give them the vaccination' - P8:23

Some community-based healthcare workers advocate for a situation where health education and study of diseases should be enshrined in school curriculum across Nigeria.

'Let there be a curriculum where people study diseases or health. More education on diseases and change of strategies by health organisations should be helpful'. - P30:29 


\subsubsection{Language}

The community-based healthcare workers stated that disseminating health information in the language of the audience is very important in gaining their trust and establishing a sense of ownership of the project among the target community.

'There is need to train locals who understand the language of the locality (community) where the health campaigns will be undertaken' - P18: 19

'The primary thing is language; when you speak the language of the people you are delivering health education to, they will understand you better and see you as one of their own' - P8: 27

\subsubsection{Funding health programmes}

The community-based healthcare workers emphasised the need for private individuals to support health foundations with their resources.

'In America and Europe, there are so many organisations that raise money for different health issues; some create awareness on diabetes, others on hypertension, many others on HIV and hepatitis. You ask yourself where they get the money from. It is people like me and you that sponsor such programmes if we can start that in Nigeria, it can be really nice' - P37: 18

Some community-based healthcare workers suggest that relieving private hospitals of taxes will help them reinvest their profit to hire more healthcare workers that will be saddled with the responsibilities of health promotion. The community-based healthcare workers are of the opinion that most healthcare facilities especially privately-owned ones are understaffed. Also, they suggested that offering free and compulsory medical services will be helpful.

'The government should support private hospitals and relieve them of taxes. If the hospitals are fully staffed, they can reach out to many patients, but a hospital that has only one doctor, for example, won't have the time to give health information to patients' - P45: 11

\section{DISCUSSION}

The people's preferences for sources of health information may change depending upon how urgent, embarrassing or complex the health concern is. Studies on the sources of certain health information such as sexual and reproductive health information have been documented in some parts of Nigeria [9]. However, there is limited information about sources of CV health information in Nigeria in general and Lagos State in particular. An example of such a few studies is a cross-sectional survey carried out in southwestern Nigeria, conducted by Oladapo and colleagues which found that the commonest source of hypertension and CV health information was the family/friend/opinion leaders of trusted groups [ $(\mathrm{n}=1198(59.9 \%)]$. The study found that $24.6 \%(n=492)$ of the participants source their health information from media including radio, public enlightenment programmes, and newspapers while $9.1 \%(n=183)$ source information from the doctor/nurse/ health worker [10]. While the highest number of the participants in this current study preferred to source their health information from the healthcare workers including the medical doctors, nurses, and pharmacist, the number of participants in the previous study that accessed hypertension and CV health information from the same source were smallest. The discrepancies may be as a result of methodological issues. For example, the current study investigated 'preferred sources' of CV health information whereas the previous study investigated 'actual sources' of hypertension and CV health information. The least preferred source of the $\mathrm{CV}$ health information in the current study is from friends, family members, and community leaders. However, these sources of $\mathrm{CV}$ health information represent the highest actual source of information in the previous study.

There are numerous reports of organisations that promote awareness around different kinds of health issues including heart health, sexual health, and nutrition among many others in Nigeria [11]. Eng and colleagues recognise that church-based health promotion interventions can reach broad populations and have great potential for reducing health inequalities [12]. Lasater and colleagues agree with this position and noted that many African-based churches contribute to the social, economic, and political welfare of their members in particular and the community at large [13]. Faith-based organisations have a long history of independently and collaboratively hosting health promotion programmes in areas such as health education and screening for different health issues including HIV [14]. A synthesis of reviewed and non-reviewed study on the use of mass media campaigns to change health behaviour carried out by Wakefield and colleagues found that mass media campaigns can produce positive changes or prevent negative changes in health-related behaviours across large populations [15]. Availability of community-based programmes and policies that support 
behaviour change contributed to these outcomes. The authors suggested that investment in longer, betterfunded campaigns would help to achieve adequate population exposure to media messages.

Concerning social media as a channel for health communication, a commentary carried out by Dosemagen and Aase explained that health industry is increasingly turning to social media to support, promote and increase the dissemination of information and data to improve both personal and community health practices [16]. The authors opined that social media provides a platform to share preventative information and enabled the creation of support structures to track personal health and build patient-to-patient support networks post-diagnosis. The authors, however, recognised the challenges of using social media for information dissemination including the potential for wrong information relating to public health spreading quickly as well as concerns about patient privacy protection.

Fox and Dogan reported a national survey of 3,014 adults living in the United States. The study involved the use of telephone interviews to investigate 1,808 participants using landline and 1, 206 participants using a cell phone. The study reported that $35 \%$ of the U.S adults say that ane time or another they have gone online to find out what medical condition they or someone else might have. In addition, $46 \%$ of the participants agreed that the information they found led them to think they needed the attention of medical professional whereas $38 \%$ of the participants say that it is something they could take care of at home. When the participants were asked about the accuracy of their initial diagnosis, $41 \%$ say a medical professional partially confirmed it whereas 35\% say they did not visit a clinician to get a professional opinion [17].

However, the proliferation of low-quality healthcare information on the internet is one of the barriers to health communication. As the volume of internet content increases on a daily basis, health information users need help to evaluate the reliability of the information they accessed [18]. Many people around the globe use the internet for health-related reasons. As a result, the potential for harm from inaccurate information and inappropriate services is significant. Because health information is normally relayed in the form of written communication, the illiterate or semi-illiterate often cannot access the information. As a result of this issue, it is important that health literature is custom-made for each target audience and written in style appropriate to their level of comprehension [18].

\section{CONCLUSION}

The dissemination of health information using numerous channels is essential in ensuring population-wide primary and secondary prevention of diseases. It is a policy that may be adopted by all the organisations, including federal and the 36 states Ministries of Health and non-governmental organisations involved in health promotion to influence people's health-seeking behaviours in Nigeria. The prerequisite for eliminating health inequalities, reducing transmissions of communicable diseases, promoting and protecting health is for public health professionals to expand their use of health communication strategies with the aim of affecting individuals, community, organisations and policy formulations. This approach can contribute to addressing the multiple determinants of health that give rise to health inequalities. In addition, it is essential for the federal and various states Ministries of Health in Nigeria to always be on alert to dispel false health information especially when there is disease outbreak in Nigeria.

\section{REFERENCES}

[1] L. B. Snyder, "'Health Communication Campaigns and Their Impact on Behavior," J Nutr Educ Behav., vol/issue: 39(2), 2007.

[2] Healthcare Access in Rural Communities Introduction, Available from: https://www.ruralhealthinfo.org/topics/healthcare-access\#barriers

[3] V. S. Freimuth and S. C. Quinn, "The contributions of health communication to eliminating health disparities," American Journal of Public Health, vol. 94, pp. 2053-5, 2004.

[4] Centers for Disease Control and Prevention, "The Health Communicator's Social Media Toolkit," Centers Dis Control Prev., pp. 32, 2011.

[5] N. V. Ivankova, et al., "Using Mixed-Methods Sequential Explanatory Design: From Theory to Practice," Field methods, vol/issue: 18(1), pp. 3-20, 2006.

[6] Purposive sampling, "Laerd Dissertation," 2013. Available from: http://dissertation.laerd.com/purposivesampling.php

[7] D. Polit, et al., "Nursing research: generating and assessing evidence for nursing practice," Philadelphia, Wolters Kluwer/Lippincot Williams \& Wilkins, 2012.

[8] Braun V. and Clarke V., "Full-Text. Qual Res Psychol," vol/issue: 3(2), pp. 77-101, 2006. Available from: http://eprints.uwe.ac.uk/11735 
[9] Z. Iliyasu, et al., "Premarital sexual experience and preferred sources of reproductive health information among young men in Kumbotso, northern Nigeria," Nigerian Journal of Medicine: Journal of the National Association of Resident Doctors of Nigeria, vol. 21, pp. 343-9, 2012.

[10] O. Oladapo, et al., "Knowledge of Hypertension and other Risk Factors for Heart Disease among Yoruba Rural Southwestern Nigerian Population,” Br J Med Med Res, vol/issue: 3(4), pp. 983-1003, 2013.

[11] Nigeria Heart Foundation, "Heart Health Promotion," 2016. Available from: http://www.nigerianheart.org/HeartHealthPromotion.html

[12] E. Eng, et al., "Institutionalizing Social Support Through the Church and into the Community," Health Education \& Behavior, vol. 12, pp. 81-92, 1985.

[13] T. M. Lasater, et al., "Synthesis of findings and issues from religious-based cardiovascular disease prevention trials," Annals of Epidemiology, vol. 7, pp. S46-53, 1997.

[14] E. E. Ezeanolue, et al., "Effect of congregation-based intervention on the uptake of HIV testing and linkage to care in pregnant women in Nigeria," Diagn Microbiol Infect Dis., vol/issue: 3(11), pp. e692-e700, 2015.

[15] M. A. Wakefield, et al., "Use of mass media campaigns to change health behavior," Lancet, vol/issue: 376(9748), pp. 1261-71, 2010.

[16] S. Dosemagen, "How Social Media Is Shaking Up Public Health and Healthcare | HuffPost," Available from: https://www.huffingtonpost.com/shannon-dosemagen-/how-social-media-is-shaki_b_9090102.html

[17] Health Online, "Pew Research Center [Internet]" national survey by the Pew Research Center's Internet \& American Life Project," Fox S. and Duggan M., 2013.

[18] Unite For Sight, "Health Communication Strategies," Available from: http://www.uniteforsight.org/healthcommunication-course/module. 